\title{
Safety monitoring control technique of construction speed of soft groundsill damming in Shuangwangcheng reservoir
}

\author{
Fang $\mathrm{Xu}^{1, \mathrm{a}}$, Wang-lin $\mathrm{Li}^{2, \mathrm{~b}}$, Fei Yan ${ }^{3, \mathrm{c}}$ Bo-fan Zhang ${ }^{4, d}$, Zhan-lei Liu ${ }^{5, \mathrm{e}}$ \\ ${ }^{1}$ College of Resource and Environment, University of Jinan, 250002, Jinan, China; \\ ${ }^{2}$ Corresponding Author, Professor, College of Resource and Environment, University of \\ Jinan, Senior engineer, Shandong Survey and Design Institute of Water Conservancy, \\ Jinan 250002, China; \\ ${ }^{3}$ China Eastern Route Corporation of South-to-North Water Diversion, 100011, Beijing, \\ China; \\ ${ }^{4}$ College of Resource and Environment, University of Jinan, 250002, Jinan, China; \\ ${ }^{5}$ College of Resource and Environment, University of Jinan, 250002, Jinan, China. \\ aemail: xufang13121@163.com, ${ }^{\text {bemail:cswlwe@sina.com, }{ }^{c} e m a i l: y a n f e i 929 @ y a h o o . c n, ~}{ }^{d}$ email: \\ 2195918394@qq.com, eemail: Dick_heart@163.com.
}

Keywords: soft groundsill damming, construction speed, safety monitoring control, excess hydrostatic pore water pressure, stability of dam slope

Abstract: Controlling construction speed is a key factor to ensure the stability of dam slope in soft groundsill. In this paper, for the construction of soft groundsill damming in Shuangwangcheng reservoir, a dynamic monitoring method of soft groundsill damming, considering the excess hydrostatic pore water pressure and anti-slide stability safety surplus degree of dam slope during the construction, was proposed. First, the real-time excess hydrostatic pore water pressure in soft soil layer during the construction was obtained by monitoring. Second, the real-time stability safety factors of dam slope during the construction was obtained by analyzing the stability of dam slope. Finally, according to the stress levels of excess hydrostatic pore water pressure and stability safety factors of dam slope during the construction, different monitoring and early-warning threshold values were set, then the construction safety level was evaluated and different monitoring control predetermined plan were employed to take different engineering measures to ensure the safety of dam. This method can ensure the stability of the dam foundation and improve construction efficiency, shorten the construction period and save the project cost.

\section{Introduction}

The permeability, the bearing capacity and the shear strength of the soft clay were low. Damming in softy clay foundation, the excess pore water pressure would be produced in soft clay. If the construction speed was too fast, excess pore water pressure dissipation speed would be smaller than that of damming, thereby reducing the effective shear strength of soft clay, furthermore, some serious problems appear, such as dam body crack, landslide and so on. It not only affect the project schedule and dam construction quality, but also increase the cost. Therefore, it is necessary to monitor the dam construction speed to control the construction safety of dam.

Generally, the method of calculating specific indicators and the method of construction monitoring were used to control the safety speed of damming. Xiong et al. [1] proposed a method that using safety monitoring technique to monitor the construction speed of dam, and took Wuping reservoir (Yun Nan Province) as an example and had achieved good results. Pore pressure coefficient B-bar control method was proposed to monitor the construction speed of dam by Peng [2] and Wang et al. [3]. In this paper, for the construction of soft groundsill damming in Shuangwangcheng reservoir, a dynamic monitoring method of soft groundsill damming was proposed to improve the construction efficiency and ensure the construction safety of soft foundation. 


\section{Engineering situation}

Shuangwangcheng reservoir was expanded on the basis of the original Shuangwangcheng reservoir, was located in Koujia village of Yangkou town north Shouguang city, and about $31 \mathrm{~km}$ from the urban district. The reservoir was a medium-sized plain reservoir, the highest design water level was $12.50 \mathrm{~m}$, corresponding maximum capacity of reservoir was $6.15 \times 10^{7} \mathrm{~m}^{3}$, design dead water level was $3.90 \mathrm{~m}$, the dead storage was $8.30 \times 10^{6} \mathrm{~m}^{3}$, the regulating storage was $5.32 \times 10^{7} \mathrm{~m}^{3}$, and the length of dam axis was $9636.0 \mathrm{~m}$.

Design overview of dam: The design water level was $12.50 \mathrm{~m}$. Crest elevation of south, north, east and west dam were $15.0 \mathrm{~m}$. Both the ratio of upstream slope and downstream slope of the dam body were 1:3. The weight was arranged on upstream and downstream dam toe. The top width of upstream dam toe weight platform was $15.0 \mathrm{~m}$. The top width of downstream dam toe weight platform was $10.0 \mathrm{~m}$. Thin plastic concrete cutoff wall was used as dam foundation seepage control scheme of Shuangwangcheng reservoir, the length of the wall was $9636.0 \mathrm{~m}$, the average depth was $28.0 \mathrm{~m}$ and the thickness was $0.30 \mathrm{~m}$.

\section{Monitoring control design}

\section{The monitoring control method of damming construction}

In this paper, Bishop Method was employed to analyze stability of dam slope which considering excess hydrostatic pore water pressure during construction. A dynamic monitoring control method of soft groundsill damming, considering the excess hydrostatic pore water pressure during construction and the anti-slide stability safety surplus degree of dam slope, was proposed. First, the real-time excess hydrostatic pore water pressure in soft soil layer during the construction was obtained by monitoring. Second, the real-time stability safety factors of dam slope during construction was obtained by analyzing the stability of dam slope. Finally, according to the stress levels of excess hydrostatic pore water pressure and stability safety factors of dam slope during the construction, different monitoring and early-warning threshold values were set, then the construction safety level was evaluated and different monitoring control predetermined plan were employed to take different engineering measures to ensure the safety of dam.

\section{Monitoring control scheme of damming}

Real-time stability safety factors of dam slope could be obtained by analyzing stability of dam slope during construction. Four warnings that were green light warning, yellow light warning, red light warning and suspension of construction warning respectively were set according to the excess hydrostatic pore water pressure stress level and stability safety surplus degree of dam slope during construction. For different warnings, the different monitoring control measures were adopted.

Warning levels

(1)No excess hydrostatic pore water pressure

If anti-slide stability safety factor (k) of dam slope was greater than or equal to 1.25 , setting it as a green light warning. When the $\mathrm{k}$ is greater than or equal to 1.05 less than 1.25 , setting it as a yellow light warning.

(2)Excess hydrostatic pore water pressure $(<50 \mathrm{kPa})$

If anti-slide stability safety factor (k) of dam slope was greater than or equal to 1.25 , setting it as a green warning. When the $\mathrm{k}$ was greater than or equal to 1.05 less than 1.25 , setting it as a yellow light warning. When the $\mathrm{k}$ was greater than 1.0 less than 1.05 , setting it as a red light warning.

(3)Excess hydrostatic pore water pressure $(50 \sim 100 \mathrm{kPa})$

When the $\mathrm{k}$ was greater than 1.0 less than 1.05 , setting it as a red light warning. When the $\mathrm{k}$ was greater than or equal to 1.05 less than 1.25, setting it as a yellow light warning. If the $\mathrm{k}$ was less than 1.0, it must be immediately stop to construct, and it was necessary to take the safety measures to increase the stability of dam slope. 
Monitoring and control measures

(1)Green light warning

The green light warning was safety warning, it could be safely constructed.

(2) Yellow light warning

For the yellow light warning, it must be judged combined with the monitoring results of dam toe horizontal displacement. According to technical specification for earth-rockfill dam safety monitoring (SL-551-2011) [4], monitoring frequency of surface deformation during construction was 6-3 times/month. On considering the importance of Shuangwangcheng reservoir, the monitoring frequency was improved, monitoring frequency of dam slope horizontal displacement was 10 times/month, namely, monitoring period was $72 \mathrm{~h}$. If the dam toe deformation at a slow and steady rate, it was ready to start up a rescue plan. If there was a trend of accelerated deformation, the construction work needed stopping and remedial measures for safety needed taking.

(3) Red light warning

For the red light warning, it must be judged combined with the monitoring results of horizontal dam toe displacement. Horizontal displacement monitoring frequency of dam slope was 30 times/month, namely, monitoring period was $24 \mathrm{~h}$. If the dam toe deformation at a slow and steady rate, it needed to ready to start up rescue plan. If there was a trend of accelerated deformation, the construction work needed stopping and remedial measures for safety needed taking.

(4) Suspension of construction warning

Safety measures must be taken for suspension of construction warning.

\section{Typical monitoring sections}

Dam design stake number $1+344$ was selected as a typical monitoring section, according to geological condition and construction schedule of dam. The layout of monitoring equipment of monitoring section 1+344 was shown in Fig.1. Five pore water pressure gauges and two soil pressure gauges were buried in this section, moreover, a well for observing underground water level was arranged.

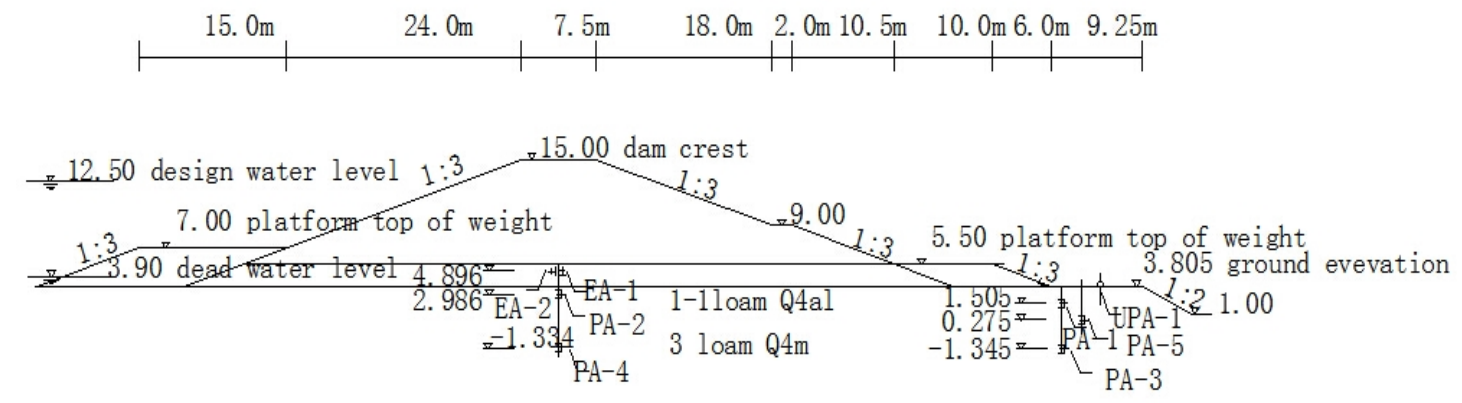

Fig.1 Layout of site monitoring equipment in 1+344 monitoring section

\section{Field monitoring results and analysis}

Fig. 2 showed the soil pressure process line of 1\# and 2\# in 1+344 monitoring section. Fig. 3 showed the groundwater level process curve of piezometric tubes outside dam toe in $1+344$ monitoring section. Fig.4 showed the pore water pressure process line of 1\#, 3\# and 5\# in 1+344 monitoring section, and Fig. 5 showed the pore water pressure process line of $2 \#$ and $4 \#$ in $1+344$ monitoring section. 


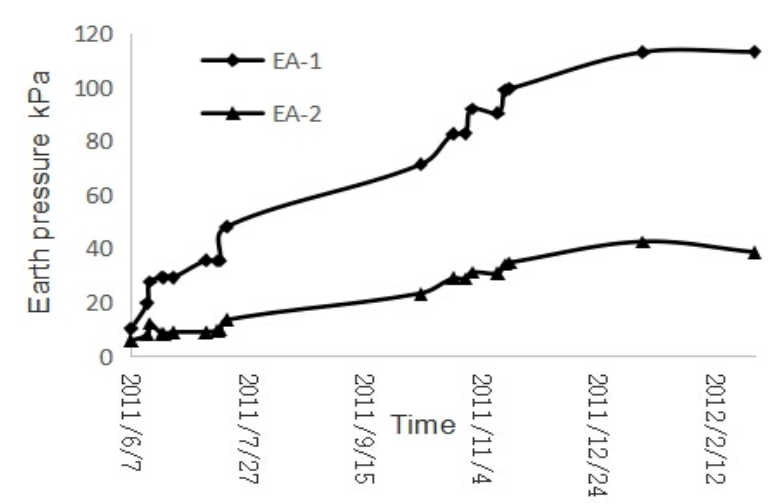

Fig. 2 Soil pressure process line of $1 \#$ and $2 \#$ in $1+344$ monitoring section

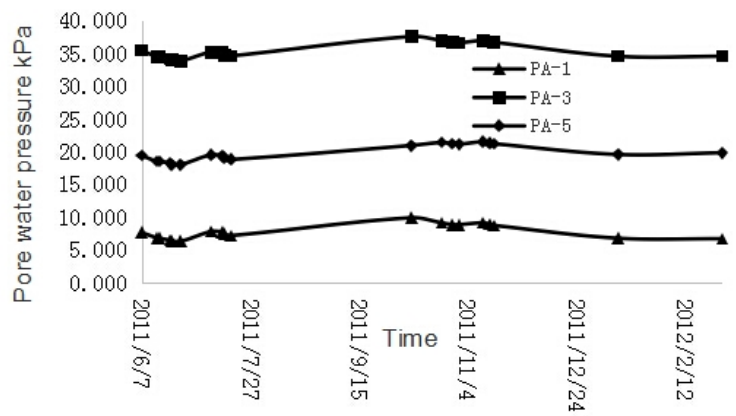

Fig.4 Pore water pressure process line of $1 \#, 3 \#$ and $5 \#$ in $1+344$ monitoring section

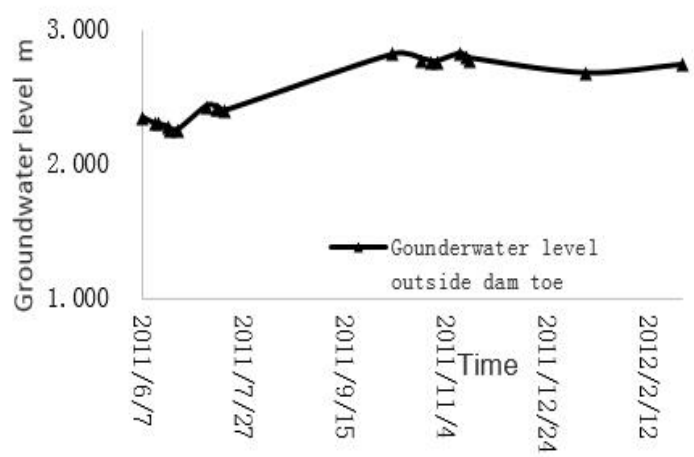

Fig.3 Groundwater level process curve of piezometric tubes outside dam toe in $1+344$ monitoring section

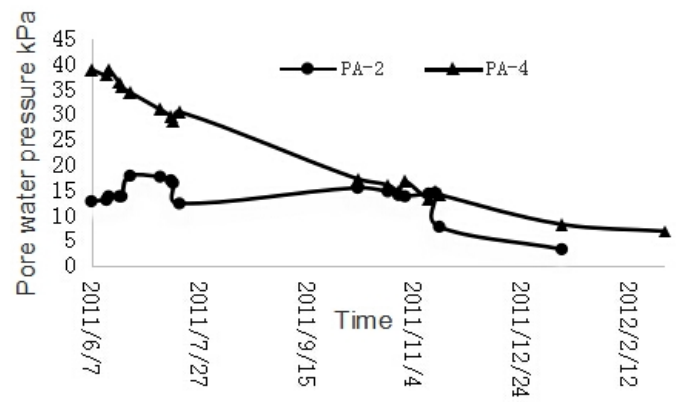

Fig.5 Pore water pressure process line of $2 \#$ and $4 \#$ in $1+344$ monitoring section

\section{Field monitoring results and analysis of soil pressure}

As was shown in Fig.2, the ratio of horizontal pressure and vertical pressure was 0.30 .

Field monitoring results and analysis of pore water pressure

The following conclusion can be drawed by analyzing the monitoring results.

(1) The change of piezometric tubes groundwater level outside dam toe

(1)As was shown in Fig.3, the change of piezometric tubes groundwater level outside of dam toe in 1+344 monitoring section showed a rising-stability-rising trend during the observation period (from June 7, 2011 to February 29, 2012). It was correlated with climate, groundwater level rose in rainy season (from July to September), and decreased in winter and spring.

(2) The change trend of groundwater level in piezometric tubes was basically consistent with that of 5\# pore water pressure gauges. Through analysis and calculation, the grounder water elevation of piezometric tubes was slight different with that of $5 \#$ pore water pressure gauges, and there was a certain error.

(2) The change pore water pressure outside dam toe

(1) It could be seen from Fig. 4: pore-water pressure changes at dam toe that was revealed by1\# and 3\# pore water pressure gauges showed an apparent consistency with the changes of water level outside dam toe. And the pore water pressure was greatly influenced by the outside.

(2) Showed from Fig.3 and the location of 1\# and 3\# pore water pressure gauges, both 1\# and 3\# pore water pressure gauges were below the groundwater level. The pore water pressure mainly reflected hydrostatic water pressure in soft soil at the corresponding position.

(3)The change of pore water pressure of dam center line

It could be seen in Fig.5, from the end of November 2011 to the end of February 2012, during suspension of construction, the pore water pressure decrease gradually. 
Those above illustrate that: during construction, pore water pressure of $2 \#$ pore water pressure gauges was rising, but during suspension of construction, it was decreasing gradually, those showed that damming could affect pore water pressure in soil.

\section{Safety monitoring control and warning services of the typical section}

When the damming height did not exceed $1 / 2$ of the dam height, the pore water pressure of the dam foundation was not exceeded $5 \mathrm{kPa}$. According to the monitoring program and warning services, dam slope anti-slide stability safety factor exceeded 1.25, the dam construction met the requirements of the specification, it started up the green light warning. When construct dam height exceed $1 / 2$ of the dam height, the pore water pressure of the dam foundation was also not exceeded $5 \mathrm{kPa}$, dam slope anti-slide stability safety factor was smaller than 1.25 , according to the monitoring program and warning services, it started up the yellow light warning. In the whole construction process, it did not start up the red light warning as well as suspension of construction warning.

\section{Conclusion}

In this paper, for the construction of soft groundsill damming in Shuangwangcheng reservoir, a dynamic monitoring method of soft groundsill damming, considering the excess hydrostatic pore water pressure and anti-slide safety surplus degree of dam slope during the construction, was proposed. The real-time excess hydrostatic pore water pressure in soft soil layer during the construction was obtained by monitoring. The real-time stability safety factors of dam slope during the construction was obtained by analyzing the stability of dam slope. Setting different monitoring and warning threshold values and four warnings that were green light warning, yellow light warning, red light warning and suspension of construction respectively, according to the stress levels of excess hydrostatic pore water pressure and stability safety factors of dam slope during construction. For different warning conditions, monitoring horizontal displacement of dam toe and engineering measures that prevent dam slope instability were correspondingly adopted. This method ensures the safety of soft clay damming, improves the construction efficiency, shortens the construction period and saves the project cost. It can be used for reference in monitoring control of other soft groundsill damming.

\section{Acknowledgements:}

This work was financially supported by Shandong province science and technology development pla ns (2013GSF11606), natural science foundation of Shandong province (ZR2014EFM023) and Public special scientific Research of Ministry of Water Resources (201401024).

\section{References:}

[1] Cheng-lin Xiong, Wan-shun Wang, Dong-cheng Tian, Jian-hui Sun: China Rural Water and Hydropower, No.3 (2004), 59-61.

[2] Hong Peng, Yuan-guo Liu, Hong-yang Xiong: Journal of Yangtze River Scientific Research Institute, Vol.22 No.6 (2005), 37-40.

[3] Hong-jia Wang: China Water Transport, Vol.5 No.6 (2007), 31-32.

[4] SL551-2011. Technical specification for earth-rockfill dam safety monitoring. Beijing: The Ministry of Water Resources of the People's Republic of China, 2011. 